\title{
CELLULAR UPTAKE STUDY AND CYTOTOXICITY STUDY OF RESVERATROL-GOLD-PEG-FOLATE (RSV- AU-PEG-FA) NANOPARTICLES ON HELA HUMAN CERVICAL CANCER CELL LINE
}

\author{
DARA A. PUTRI, SUTRIYO SUTRIYO*, FADLINA C. SAPUTRI
}

Faculty of Pharmacy, Universitas Indonesia, Depok, 16424, West Java, Indonesia

Email: sutriyo@farmasi.ui.ac.id

Received: 02 Mar 2020, Revised and Accepted: 05 May 2020

\begin{abstract}
Objective: This study aimed to evaluate the effectivity of resveratrol-gold-PEG-folate (RSV-Au-PEG-FA) nanoparticles formulation in resveratrol (RSV) targeted delivery and cytotoxicity effect on HeLa human cervical cancer cell line.

Methods: Gold nanoparticles (AuNP) were used as carriers and folic acid (FA) was used as active targeting moiety, using polyethylene glycol-bisamine (PEG-bis-amine) as linker. RSV-Au-PEG-FA nanoparticles were characterized by UV-Vis spectrophotometry, infrared spectroscopy, particle size analyzer (PSA), and transmission electron microscopy (TEM). Cellular uptake study was conducted by using fluorescence microscope. Cytotoxicity study was conducted by 3-(4,5-Dimethylthiazol-2-yl)-2,5-diphenyltetrazolium bromide (MTT) assay.
\end{abstract}

Results: Cellular uptake study has shown that RSV-Au-PEG-FA nanoparticles are potential to be accumulated intracellularly in HeLa cells more than in Vero cells. Cytotoxicity study has shown RSV-Au-PEG-FA nanoparticles IC $5_{00} 67.06 \pm 2.14 \mu \mathrm{M}$ and RSV IC $509.66 \pm 1.44 \mu \mathrm{M}$ on HeLa cells

Conclusion: RSV-Au-PEG-FA nanoparticles are potential to enhance RSV uptake by HeLa cells selectively.

Keywords: Resveratrol, Gold nanoparticles, Folic acid, Active targeting, Cellular uptake, Cytotoxicity, HeLa cells

(C) 2020 The Authors. Published by Innovare Academic Sciences Pvt Ltd. This is an open access article under the CC BY license (http://creativecommons.org/licenses/by/4.0/) DOI: http://dx.doi.org/10.22159/ijap.2020v12i4.37307. Journal homepage: https://innovareacademics.in/journals/index.php/ijap

\section{INTRODUCTION}

Resveratrol (trans-3,5,4'-trihydoxystilbene) is lipophilic polyphenol obtained from grape plant (Vitis vinifera) and melinjo seeds (Gnetum gnemon L.) [1-3]. The activities of resveratrol (RSV) as anticancer have been reported. RSV has the ability to inhibit the expression of anti-apoptotic proteins and increase the expression of pro-apoptotic proteins [4, 5]. RSV is able to increase p53 protein level and inhibit the proliferation of cancer cells by increasing cells accumulation at G1/S phase via aryl hydrocarbon receptor (AHR) [6]. RSV is also able to inhibit the transcription of enzyme which contributes in metastasis process from tumor [7].

However, RSV lacks the ability to target cancer cells selectively, which limits its usage as anticancer. RSV induces apoptosis when used at high dose $(10-100 \mu \mathrm{M})$ on cancer cells and normal cells [8, 9]. RSV usage at $\geq 10 \mu \mathrm{M}$ induces apoptosis of normal rat thymocytes [9]. RSV usage in great concentration $(60 \mu \mathrm{M})$ inhibits the growth and induces apoptotic effect on CD34+precursor cells [10]. RSV inhibits proliferation and causes toxic effect on $10 \mathrm{ScNCr} / 23$ mouse macrophages ( $\mathrm{IC}_{50} 29.0 \mu \mathrm{M}$ ) [11]. Active targeting system might be an alternative effort to overcome this limitation.

Gold nanoparticle (AuNP) is metal nanoparticle which is well-known for its biocompatible, easy to prepare, and ready to modify with active ligand. AuNP has intense and specific surface plasmon resonance absorption, hence, easy to characterize [12-15]. Folic acid (FA) usage as active targeting moiety is based on specific overexpression of folate-binding protein found in epithelial cancer cells (MDA-MB-231, KB 3-1, and HeLa cells) [16-19]. The study of combination usage of AuNP as RSV nanocarriers and FA as targeting moiety have been done previously where resveratrol-gold-PEGfolate (RSV-Au-PEG-FA) nanoparticles were successfully prepared. However, the effectivity of RSV-Au-PEG-FA nanoparticles in improving selectivity of RSV on cancer cells haven't been studied yet [20].

In this study, RSV was formulated by using AuNP as carriers, FA as targeting moiety, and PEG-bis-amine as linker. The RSV-Au-PEG-FA nanoparticles were characterized by UV-Vis spectrophotometry, infrared spectroscopy, particle size analyzer (PSA), and transmission electron microscopy (TEM). In order to see the effectivity of RSV-Au-
PEG-FA nanoparticles, cellular uptake study and cytotoxicity study was conducted on HeLa human cervical cancer cell line.

\section{MATERIALS AND METHODS}

\section{Materials}

Resveratrol (RSV) $\geq 99 \%, \mathrm{HAuCl}_{4}$ 30\%, PEG-bis-amine (MW 3400 $\mathrm{g} / \mathrm{mol}$ ), folic acid (FA) $\geq 97 \%$ (MW $441.40 \mathrm{~g} / \mathrm{mol}$ ), N-(-3Dimethylaminopropyl)- $\mathrm{N}$-ethylcarbodiimide $\quad$ (EDC), $\mathrm{N}$ hydroxysuccinimide (NHS) 98\%, trisodium citrate (Sigma Aldrich, Singapore), cisplatin (Dankos, Indonesia), HeLa (ATCC ${ }^{\circledR}$ CCL-2 $^{\text {TM}}$ ) human cervical cancer cell line, Vero $\left(\mathrm{ATCC}^{\circledR} \mathrm{CCL}^{\left.-81^{\mathrm{TM}}\right)}\right.$ normal kidney epithelial cell line from African green monkey (American Type Culture Collection, USA), dulbecco's modified eagle medium (DMEM), fetal bovine serum (FBS) 10\%, penicillin-streptomycin 1\%, phosphate buffered saline (PBS), trypsin $0.125 \%$, typan blue $0.1 \%$, paraformaldehyde $4 \%$, fluorescein isothiocyanate (FITC), and [3- $(4,5-$ Dimethylthiazol-2-yl)-2,5-diphenyltetrazolium bromide] (MTT) 0.5\%.

\section{Preparation of PEG-FA conjugate}

Twenty-five milligrams of FA were conjugated to 250 mg PEG-bisamine (1.5:1.0 in molar ratio) with $300 \mathrm{mg}$ EDC and $100 \mathrm{mg}$ NHS in $0.5 \mathrm{ml}$ dimethyl sulfoxide (DMSO). The reaction was accelerated with $0.5 \mathrm{ml} \mathrm{HCl} 2 \%$ and stirred for $5 \mathrm{~h}$ at room temperature. PEG-FA conjugates were kept in $15^{\circ} \mathrm{C}$ until further usage [21].

\section{Preparation of AuNP}

Ten milliliters of $\mathrm{HAuCl}_{4} 1 \mathrm{mmol}$ was heated until it began to boil and $0.282 \mathrm{ml}$ trisodium citrate $130 \mathrm{mmol}$ was quickly added while the heating and stirring were proceeded for $15 \mathrm{~min}$ until the redburgundy AuNP was formed. The heating was stopped and the stirring continued until the temperature of mixture decreased to room temperature [22].

\section{Preparation of RSV-Au-PEG-FA nanoparticles}

One hundred milligrams of PEG-FA conjugate were added to $10 \mathrm{ml}$ AuNP and stirred for $4 \mathrm{~h}$ at room temperature. The mixture was added with $2.28 \mathrm{ml}$ RSV $600 \mu \mathrm{g} / \mathrm{ml}$ and stirred for $2 \mathrm{~h}$ at room temperature. The RSV-Au-PEG-FA nanoparticles were purified by centrifugal-ultrafiltration using Vivaspin 2 (MW 2000 Da) (2000 
rpm; $30 \mathrm{~min}$ ) to remove unreacted molecules ( $\mathrm{MW}<2000 \mathrm{Da})$ such as NHS, EDC, and unreacted FA. The residue and filtrate layers were collected respectively and kept in $15^{\circ} \mathrm{C}$ until further studies [14].

\section{RSV-Au-PEG-FA nanoparticles characterization}

RSV-Au-PEG-FA nanoparticles were detected using UV-Vis Jasco V-530 spectrophotometer and FTIR 8400S/IRPrestrige with DRS 8000. The particle size, polydispersity index (PDI), and zeta potential of RSV-AuPEG-FA nanoparticles were measured with Horiba SZ-100 particle size analyzer. The morphology of RSV-Au-PEG-FA nanoparticles were observed by Tecnai G2 20 S-Twin transmission electron microscope.

\section{\% Drug loading (\%DL)}

To determine \%DL of loaded RSV in RSV-Au-PEG-FA nanoparticles, indirect method was used. The amount of free RSV in filtrate was determined by HPLC system. HPLC system consisted of HPLC Shimadzu LC-20AT pump, UV-Vis SPD-10A detector, and Inertsil ODS-3 column with $250 \mathrm{~mm}$ in length, $5 \mu \mathrm{m}$ particle diameter, 4.6 $\mathrm{mm}$ i.d. Reversed phase HPLC was performed using isocratic eluent water: acetonitrile (3:1) pH 3 adjusted by glacial acetate acid with flow rate $1.5 \mathrm{ml} / \mathrm{min}$. The analysis was performed at $25^{\circ} \mathrm{C}$ and detected at $306 \mathrm{~nm}$. Standards and samples were filtered with 0.45 $\mu \mathrm{m}$ filter membrane and $20 \mu \mathrm{l}$ of each was injected to system [23]. For quantification, a standard calibration curve was done ranging 1 to $25 \mu \mathrm{g} / \mathrm{ml}$. The square regression coefficient of analytical curve was $r^{2}=0.9986(r=0.9992)$. Data were processed by LC-Solution software. \%DL is determined using:

$$
\% \mathrm{DL}=\left(\mathrm{W}_{\mathrm{t}}-\mathrm{W}_{\mathrm{f}}\right) / \mathrm{W}_{\mathrm{t}} \times 100 \%
$$

Where $W_{t}$ is the total amount of RSV added in the formulation and $\mathrm{W}_{\mathrm{f}}$ is the amount of free RSV in filtrate.

\section{Cell culture}

Cellular uptake study of RSV-Au-PEG-FA nanoparticles was evaluated on HeLa cells and Vero cells. Cytotoxicity study was evaluated on HeLa cells. HeLa and Vero cell lines were cultured in DMEM supplemented with FBS 10\% and penicillin-streptomycin 1\% in cell culture flask. Cells were routinely propagated and kept in incubator $\left(37^{\circ} \mathrm{C} ; 5 \% \mathrm{CO}_{2}\right)[4,24,25]$.

\section{Cellular uptake study}

One milliliter of FITC $10 \mu \mathrm{g} / \mathrm{ml}$ were added to $1 \mathrm{ml}$ of RSV-Au-PEGFA nanoparticles and kept at $15^{\circ} \mathrm{C}$ overnight [26]. Each $500 \mu$ of cell culture containing $10^{4}$ of HeLa and Vero cells, respectively, were seeded into 8 -slide chambers and incubated at $37^{\circ} \mathrm{C}$ and $5 \% \mathrm{CO}_{2}$ for $24 \mathrm{~h}$. Culture medium were removed and wells were washed 3 times by PBS. Cells were fixed by $200 \mu \mathrm{l}$ paraformaldehyde $4 \%$ and incubated for $1 \mathrm{~h}$. Culture mediums were removed and wells were washed 3 times by PBS. The HeLa and Vero cells were added with $200 \mu \mathrm{l}$ of FITC-RSV-Au-PEG-FA and incubated for $30 \mathrm{~min}$. The samples were removed and the chambers were peeled. The coverslip was placed onto fluorescence microscope slide. The light filter was set into B-2A filter to observe cellular uptake of FITC-RSV$\mathrm{Au}-\mathrm{PEG}-\mathrm{FA}$ in HeLa and Vero cells.

\section{Cytotoxicity study}

The cytotoxicity of RSV-Au-PEG-FA nanoparticles against HeLa cells was assessed by MTT assay. One hundred microliters of cell culture containing $10^{4}$ of HeLa cells were seeded into 96-well plate and incubated at $37{ }^{\circ} \mathrm{C}$ and $5 \% \mathrm{CO}_{2}$ for $24 \mathrm{~h}$. Culture mediums were removed and wells were washed 3 times with PBS [27]. The cells then incubated with mediums containing series of concentration (3 to $120 \mu \mathrm{M}$ ) of RSV-Au-PEG-FA nanoparticles, RSV, and cisplatin for $24 \mathrm{~h}$ [28]. Controls were performed by adding DMSO $0.28 \%$ to plate. The samples were removed and washed 3 times with mediums. Ten microliters of MTT $0.5 \mathrm{mg} / \mathrm{ml}$ in medium were added into each well and incubated for $4 \mathrm{~h}$. The MTT were removed and $100 \mu \mathrm{l}$ of absolute ethanol was added to each well to solute formazan crystals. The absorbances were measured with a Bio-Rad microplate reader at $595 \mathrm{~nm}$. The relative cell viability was expressed as the percentage of negative control.

\section{RESULTS AND DISCUSSION}

\section{Preparation of RSV-Au-PEG-FA nanoparticles}

In preparation of AuNP, the yellow $\mathrm{HAuCl}_{4}$ was reduced into redburgundy AuNP, indicating AuNP was successfully formed. The preparation of AuNP followed Turkevich method where trisodium citrate as weak reducing agent using heat as energy source to reduce $\mathrm{Au}^{3+}+\mathrm{HAuCl}_{4}$ into $\mathrm{Au}{ }^{\circ}$ in AuNP [29]. The PEG-FA conjugation process involving the activation of carboxyl group of FA by EDC and NHS where the carboxyl group was substituted into NHS group forming intermediate folate-NHS. The NHS group further substituted with amine group from PEG-bis-amine where new covalent amide bond was formed resulting PEG-FA conjugate [30, 31]. The redburgundy of AuNP turned into darker after added with PEG-FA conjugate and RSV, indicating the particle size was increasing and interactions among AuNP, PEG-FA conjugate, and RSV forming into RSV-Au-PEG-FA nanoparticles (fig. 1).
(1)

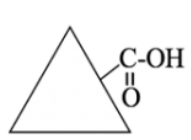

FA

(2)

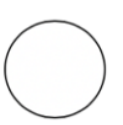

AuNP

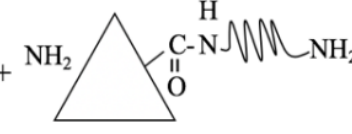

PEG-FA conjugate

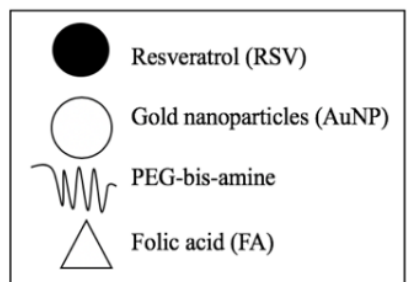

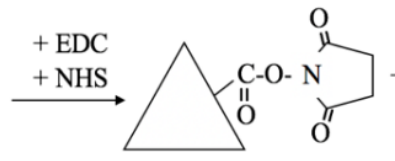

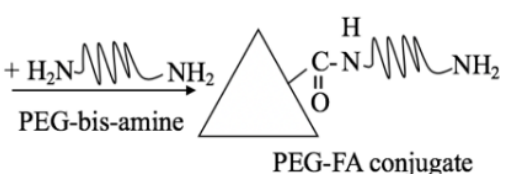

PEG-FA conjugate

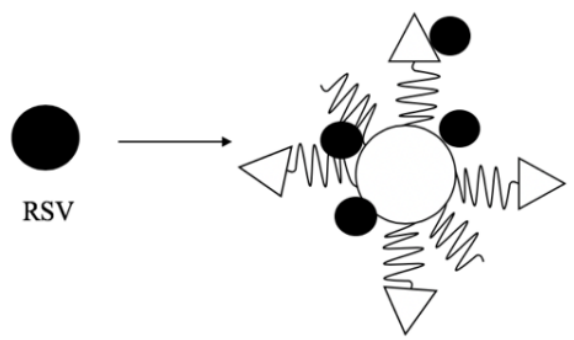

Fig. 1: Effect of tablet geometry on drug release 


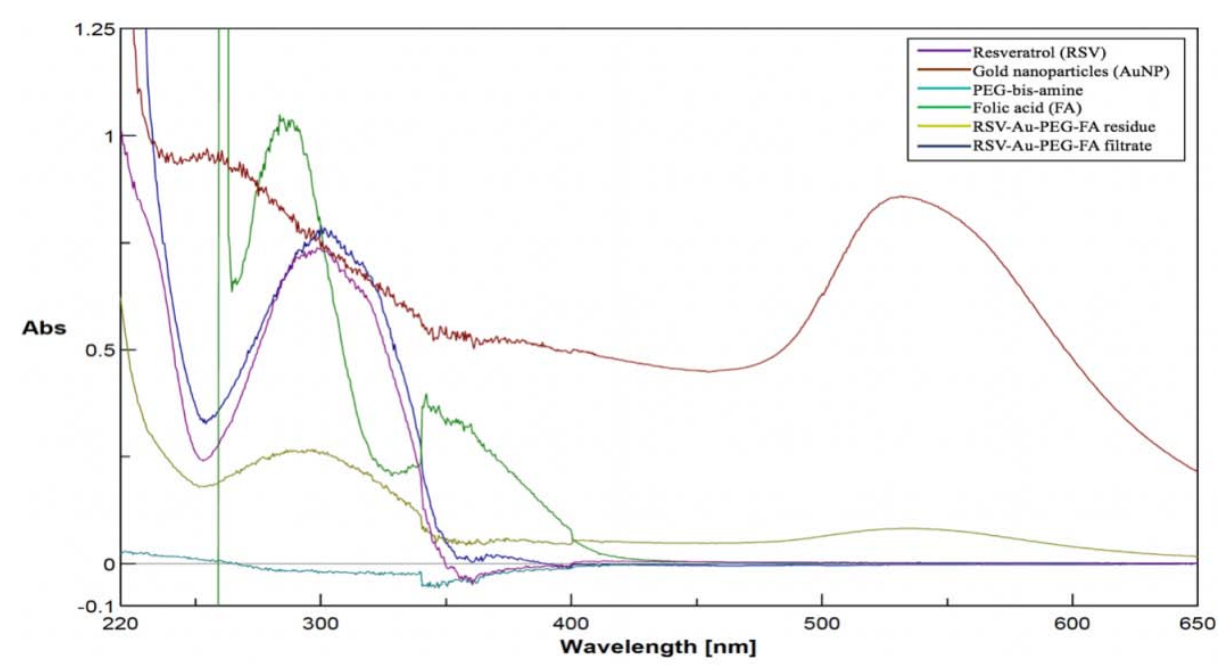

Fig. 2: UV-Vis spectrums of resveratrol, gold nanoparticles, PEG-bis-amine, folic acid, RSV-Au-PEG-FA nanoparticles residue, and RSV-AuPEG-FA nanoparticles filtrate

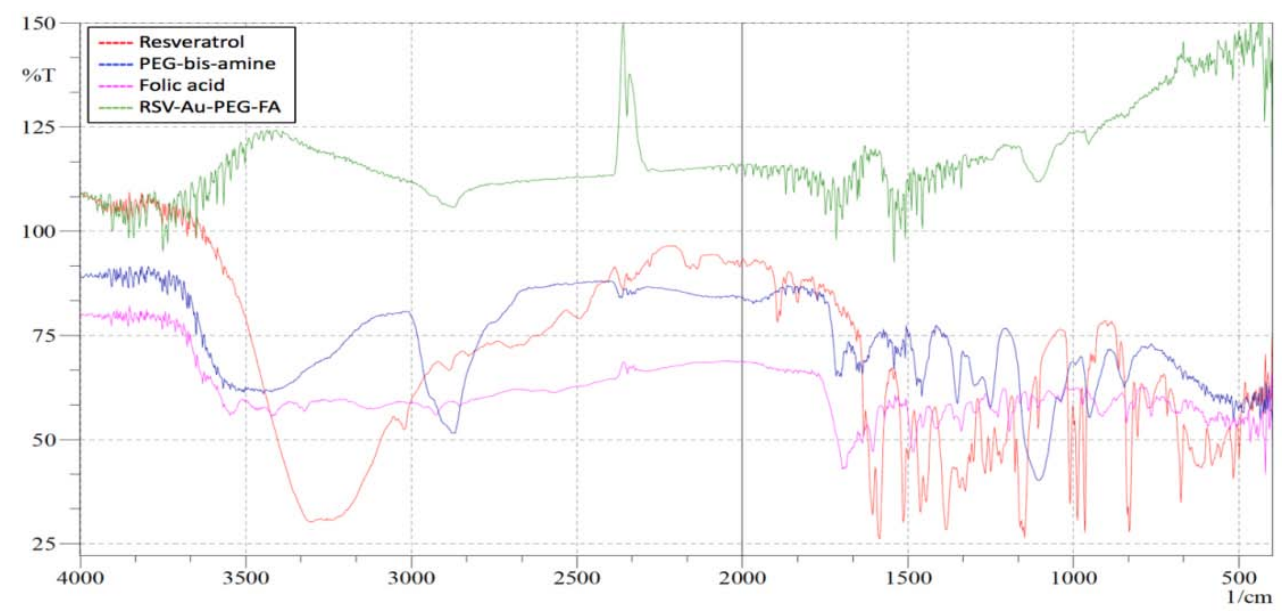

Fig. 3: Infrared spectrums of resveratrol, PEG-bis-amine, folic acid, and RSV-Au-PEG-FA nanoparticles

\section{Characterization of RSV-Au-PEG-FA nanoparticles}

The comparative UV-Vis spectrums of RSV, AuNP, PEG-bis-amine, FA, RSV-Au-PEG-FA nanoparticles residue, and RSV-Au-PEG-FA nanoparticles filtrate were presented in fig. 2. RSV and AuNP respectively showed maximum absorption at $\lambda_{\max } 298.5$ and 532 $\mathrm{nm}$. RSV-Au-PEG-FA nanoparticles in residue layer showed characteristics peak at $296.5 \mathrm{~nm}$ and $534 \mathrm{~nm}$, which was similar to peak of RSV and AuNP, indicating RSV was successfully loaded into nanoparticles. RSV-Au-PEG-FA nanoparticles filtrate showed one peak at $300 \mathrm{~nm}$ with similar characteristic with RSV, indicating centrifugal ultrafiltration method was effective to purify RSV-AuPEG-FA nanoparticles from unreacted RSV.

The comparative FTIR spectrums of RSV-Au-PEG-FA nanoparticles, RSV, PEG-bis-amine, and FA were shown in fig. 3. There was similar peak of RSV-Au-PEG-FA nanoparticles with PEG-bis-amine and FA. The peak at $1611 \mathrm{~cm}^{-1}$ and $1699 \mathrm{~cm}^{-1}$ in FA were referred to amide I and II bands, which was also found in RSV-Au-PEG-FA nanoparticles (1544 $\mathrm{cm}^{-1}$ and $1722 \mathrm{~cm}^{-1}$ ). The peak at $1107 \mathrm{~cm}^{-1}$ in PEG-bis-amine referred to $\mathrm{C}-\mathrm{N}$ stretch also found in RSV-Au-PEG-FA nanoparticles $\left(1115 \mathrm{~cm}^{-1}\right)$. Meanwhile, the peak $\mathrm{C}=\mathrm{C}$ aromatic of RSV $\left(836 \mathrm{~cm}^{-1}\right)$ was not visible in RSV-Au-PEG-FA nanoparticles, which was contrary to UV-Vis spectrophotometry result. This indicated RSV was potentially loaded in RSV-Au-PEG-FA nanoparticles [32, 33].

The particle size, polydispersity index (PDI), zeta potential, and drug loading of RSV-Au-PEG-FA nanoparticles were presented in table 1 and fig. 4. The particle size and PDI are important parameters to predict stability of nanoparticles and its clinical utilization. As seen in table 1, the $\mathrm{z}$-average of RSV-Au-PEG-FA nanoparticles was $<100 \mathrm{~nm}$, indicating that based on particle size alone, RSV-Au-PEG-FA nanoparticles were potentially prevented from cellular internalization by phagocytic cells such as macrophages, neutrophils, and dendritic cells in blood vessels, which mainly happened to nanoparticles with 100-150 nm in size. At the same time, the particle size of RSV-Au-PEG-FA nanoparticles was not less than $10 \mathrm{~nm}$, indicating that RSV-Au-PEG-FA nanoparticles was potentially large enough not to distribute to normal tissues through small pores such as glomerulus in kidney $(10-15 \mathrm{~nm})$ [34]. The PDI is a parameter used to define the degree of uniformity of particle size distribution. Large PDI value $(>0.7)$ indicates the sample has broad size range in particle size distribution, related to instability of particles in colloid system. The PDI value of RSV-Au-PEG-FA nanoparticles was $<0.7$ indicating that RSV-Au-PEG-FA nanoparticles had homogenously monodisperse system. Zeta potential is a parameter which reflect on stability of nanoparticles in colloid system and also can be used to define surface property of nanoparticles. Zeta potential values greater than $\pm 30 \mathrm{mV}$ permits stable colloid system. The zeta potential of RSV-Au-PEG-FA nanoparticles was greater than-30 $\mathrm{mV}$. This indicated that there's great repulsive forces among the particles, preventing aggregation of particles and resulting relatively stable colloid system [35]. However, the negative charge particles are prone to interact with phagocytic cells compared to 
positive charge particles in similar size, presumably because of similarity with negative charge of bacteria [36].

Based on morphology analysis using TEM, RSV-Au-PEG FA nanoparticles have spherical shape, as seen in fig. 5. Based on previous studies, particle shape may influence the movement of nanoparticles in circulation system and cellular uptake process. Rodshaped nanoparticles are more likely to marginate towards vessel wall compared to spherical nanoparticles, which may interrupt delivery and targeting process [37]. The cellular uptake of spherical gold nanoparticles is higher than rod-shaped gold nanoparticles [38]. The \% DL of RSV-Au-PEG-FA nanoparticles was $88.87 \pm 0.25 \%$.

Table 1: Particle size distribution, polydispersity index, and zeta potential of RSV-Au-PEG-FA nanoparticles

\begin{tabular}{ll}
\hline RSV-Au-PEG-FA & \\
\hline Z-average (nm) & $31.57 \pm 1.80$ \\
$\operatorname{Dv}_{10}(\mathrm{~nm})$ & $11.97 \pm 1.75$ \\
$\operatorname{Dv}_{50}(\mathrm{~nm})$ & $16.37 \pm 1.89$ \\
$\operatorname{Dv}_{90}(\mathrm{~nm})$ & $27.10 \pm 1.80$ \\
Polydispersity Index (PDI) & $0.321 \pm 2.21$ \\
Zeta Potential (mV) & $-53.63 \pm 0.40$ \\
\hline
\end{tabular}

Data represented mean \pm SD $(n=3)$

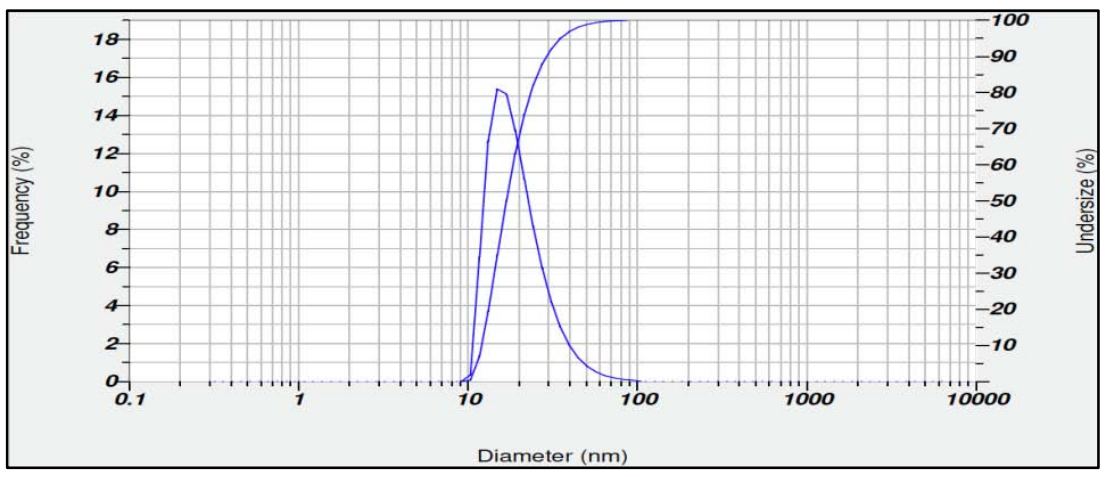

Fig. 4: Particle size distribution of RSV-Au-PEG-FA nanoparticles by volume

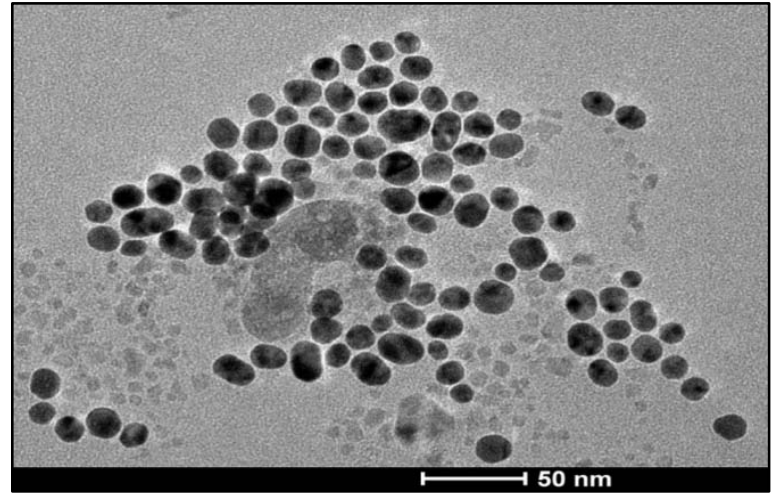

Fig. 5: TEM image of RSV-Au-PEG-FA nanoparticles
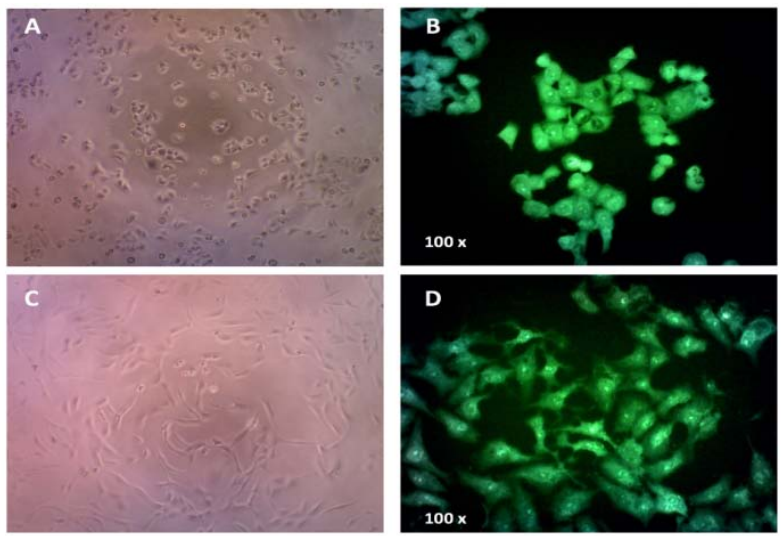

Fig. 6: Fluorescence microscopy images of (A) HeLa cells, (B) HeLa cells in FITC-RSV-Au-PEG-FA, (C) Vero cells, (D) Vero cells in FITC-RSVAu-PEG-FA 


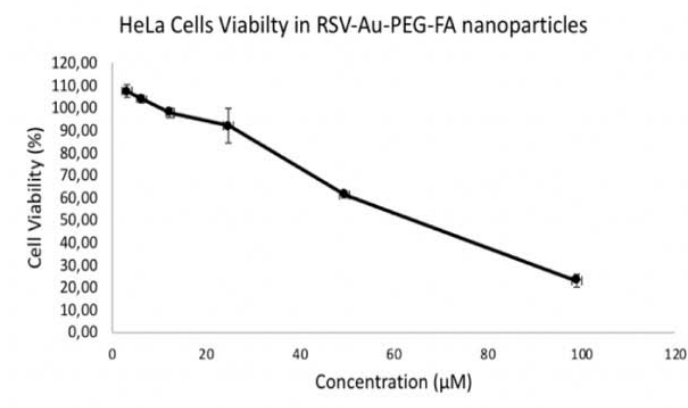

(a)

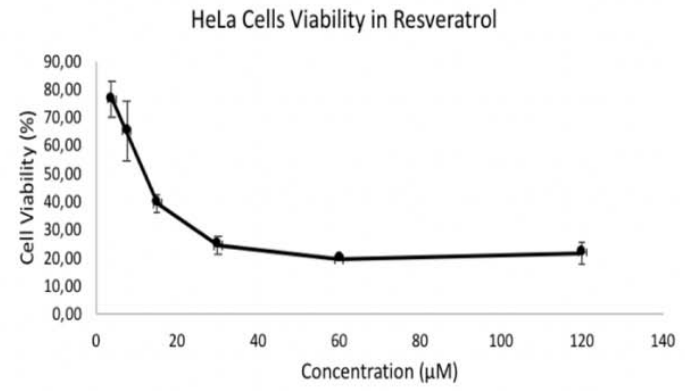

(b)

Fig. 7: Graphics of HeLa cells viability in (A) RSV-Au-PEG-FA nanoparticles and (B) free RSV, data represented mean \pm SD (n=3)

\section{Cellular uptake study}

After HeLa and Vero cells were incubated with FITC-RSV-Au-PEG-FA nanoparticles for $30 \mathrm{~min}$, FITC-RSV-Au-PEG-FA nanoparticles were both accumulated in both cells, which is shown in fig. 6. The fluorescence of FITC-RSV-Au-PEG-FA nanoparticles were more intense in HeLa cells compared to Vero cells, indicating the cellular uptake of RSV-Au-PEG-FA nanoparticles in HeLa cells was potentially greater than in Vero cells.

As reported before, high affinity folate receptor (FR) is highly expressed on numerous malignant cells, including HeLa cervical cancer cells. Meanwhile, FR receptor has been found at low levels in normal kidney, lung, and thyroid. FR located on the surface of cancer cell mediates the drug-folate conjugate in similar manner to free folic acid into the cancer cell by endocytosis. The acidic environment of endosome disassociates folate from receptor and drug is released [16, 18, 39].

In this study, RSV-Au-PEG-FA nanoparticles potentially interacted with overexpressed FRs on surface of HeLa cells which lead to endocytosis of RSV-Au-PEG-FA nanoparticles. Meanwhile, Vero cells has low levels of FRs, which subsequently caused to less interaction between RSV-Au-PEG-FA nanoparticles with FR and less endocytosis of RSV-Au-PEG-FA nanoparticles into Vero cells. This indicated that FA usage as targeting moiety was potentially suitable in RSV formulation to treat cancer selectively.

\section{Cytotoxicity study}

The cytotoxicity effect of RSV-Au-PEG-FA nanoparticles and free RSV on HeLa cells over range of concentrations were represented in fig. 7. After $24 \mathrm{~h}$ of incubation with RSV-Au-PEG-FA nanoparticles, doses up from 3.09 to $24.73 \mu \mathrm{M}$ were ineffective and toxicity appeared to start at $49.45 \mu \mathrm{M}$ with cell viability $61.17 \pm 1.18 \%$. Meanwhile with $\mathrm{RSV}$, the cell viability at concentration $60 \mu \mathrm{M}$ was already $19.64 \pm 0.29 \%$. After data plot, IC 50 RSV-Au-PEG-FA nanoparticles $(67.06 \pm 2.14 \mu \mathrm{M})$ was higher than $\mathrm{IC}_{50} \mathrm{RSV}(9.66 \pm 1.44 \mu \mathrm{M})$. The DMSO $(0.28 \%)$ didn't affect the viability of control cells. This indicated that RSV-Au-PEG-FA nanoparticles needs higher concentration than free RSV to cause toxic effect on HeLa cells. This is contrary to previous studies in which RSV in nanoparticles form were generally more toxic than free $\operatorname{RSV}[31,40]$.

With result of cellular uptake study, enhancement of RSV-Au-PEG-FA nanoparticles uptake into cancer cells doesn't guarantee RSV-AuPEG-FA nanoparticles are more potent than free RSV, because toxic effect still depends on nanocarrier's ability to release RSV into cancer cells and RSV endurance in cellular environment (lysosome and exocytosis) to be functional as anticancer [41-43].

Based on cellular uptake study and cytotoxicity study, it's predicted that RSV-Au-PEG-FA nanoparticles haven't fully released yet in endosomal environment of HeLa cells. This might be caused by linker type used was forming strong and stable bond even in cellular environment which inhibited the release of RSV from RSV-Au-PEGFA nanoparticles. In previous study, polyvinyl alcohol was used as linker and nanoparticles formed needed lower concentration than free RSV to cause toxic effect on cancer cells [40].

\section{CONCLUSION}

Cellular uptake study showed that the fluorescence of RSV-Au-PEGFA nanoparticles were more intense in HeLa cells compared to Vero cells. Cytotoxicity study has shown that $\mathrm{IC}_{50}$ RSV-Au-PEG-FA nanoparticles $(67.06 \pm 2.14 \mu \mathrm{M})$ was higher than IC ${ }_{50}$ RSV $(9.66 \pm 1.44$ $\mu \mathrm{M})$. From this research, it can be concluded that RSV-Au-PEG-FA nanoparticles are potential to enhance RSV uptake by HeLa cells selectively. However, RSV-Au-PEG-FA nanoparticles need higher concentration than RSV to cause toxic effect on HeLa cells.

\section{ACKNOWLEDGEMENT}

This research was financially supported by authors and Directorate of Research and Community Engagements, Universitas Indonesia, through Hibah PITTA in reference to 1781/UN2. R3.1/HKP.05.00/2018.

\section{AUTHORS CONTRIBUTIONS}

All authors have contributed equally.

\section{CONFLICT OF INTERESTS}

The authors report no conflicts of interest.

\section{REFERENCES}

1. Tani H, Hikami S, Iizuna S, Yoshimatsu M, Asama T, Ota H, et al. Pharmacokinetics and safety of resveratrol derivatives in humans after oral administration of melinjo (Gnetum gnemon L.) seed extract powder. J Agric Food Chem 2014;62:1999-2007.

2. Tatefuji T, Yanagihara M, Fukushima S, Hashimoto K. Safety assessment of melinjo (Gnetum gnemon L.) seed extract: acute and subchronic toxicity studies. Food Chem Toxicol 2014;67:230-5.

3. Robinson K, Mock C, Liang D. Pre-formulation studies of resveratrol. Drug Dev Ind Pharm 2015;41:1464-9.

4. Dhandayuthapani S, Marimuthu P, Hormann V, Kumi Diaka J, Rathinavelu A. Induction of apoptosis in HeLa cells via caspase activation by resveratrol and genistein. J Med Food 2013;16:139-46.

5. Li L, Qiu RL, Lin Y, Cai Y, Bian Y, Fan Y, et al. Resveratrol suppresses human cervical carcinoma cell proliferation and elevates apoptosis via mitochondrial and p53 signalling pathways. Oncol Lett 2018;15:9845-51.

6. Flores Perez A, Elizondo G. Apoptosis induction and inhibition of HeLa cell proliferation by alpha-naphthoflavone and resveratrol are aryl hydrocarbon receptor-independent. Chem Biol Interact 2018;281:98-105.

7. Kim YS, Sill JW, Sung HJ. Suppressing effect of resveratrol on the migration and invasion of human metastatic lung and cervical cancer cells. Mol Biol Rep 2012;39:8709-16.

8. Mukherjee S, Dudley JI, Das DK. Dose-dependency of resveratrol in providing health benefits. Dose Response 2010;8:478-500.

9. Fujimoto A, Sakanashi Y, Matsui H, Oyama T, Nishimura Y, Masuda $\mathrm{T}$, et al. Cytometric analysis of cytotoxicity of polyphenols and related phenolics to rat thymocytes: potent cytotoxicity of resveratrol to normal cells. Basic Clin Pharmacol Toxicol 2009;104:455-62. 
10. Ferry Dumazet H, Garnier O, Mamani Matsuda M, Vercauteren J, Belloc F, Billiard C, et al. Resveratrol inhibits the growth and induces the apoptosis of both normal and leukemic hematopoietic cells. Carcinogenesis 2002;3:1327-33.

11. Billack B, Radkar V, Adiabouah C. In vitro evaluation of the cytotoxic and anti-proliferative properties of resveratrol and several of its analogs. Cell Mol Biol Lett 2008;12:553-69.

12. Battacharya R, Patra CR, Earl A, Wang S, Katarya A, Lu L, et al. Attaching folic acid on gold nanoparticles using noncovalent interaction via different polyethylene glycol backbones and targeting of cancer cells. Nanomed: NBM 2007;3:224-38.

13. Das M, Shim KH, An SSA, Yi DK. Review on gold nanoparticles and their applications. Toxicol Environ Health Sci 2011;3:193-205.

14. Kumar CG, Poornachandra Y, Mamidyala SK. Green synthesis of bacterial gold nanoparticles conjugated to resveratrol as delivery vehicles. Colloids Surf B 2014;123:311-7.

15. Sutriyo, Mutalib A, Ristaniah, Anwar E, Radji M, Pujiyanto A, et al. Synthesis of gold nanoparticles with polyamidoamine (PAMAM) generation 4 dendrimer as stabilizing agent for CT scan contrast agent. Macromol Symp 2015;353:96-101.

16. Sonvico F, Dubernet C, Marsaud V, Appel M, Chacun H, Stella B, et al. Establishment of an in vitro model expressing the folate receptor for the investigation of targeted delivery systems. J Drug Delivery Sci Technol 2005;15:407-10.

17. Liu F, Deng D, Chen X, Qian Z, Achilefu S, Gu Y. Folatepolyethylene glycol conjugated near-infrared fluorescence probe with high targeting affinity and sensitivity for in vitro early tumor diagnosis. Mol Imaging Biol 2010;12:595-607.

18. Zwicke GL, Mansoori GA, Jeffery CJ. Utilizing the folate receptor for active targeting of cancer nanotherapeutics. Nano Rev 2012;18496:1-11

19. Banu H, Stanley B, Faheem SM, Seenivasan R, Premkumar K, Vasanthakumar G. Thermal chemosensitization of breast cancer cells to cyclophosphamide treatment using folate receptor targeted nanoparticles. Plasmonics 2014;9:1341-9.

20. Sutriyo S, Iswandana R, Ivariani FM. Synthesis and stability of resveratrol-gold nanoparticle-polyethylene glycol-folic acid conjugates. Int J Appl Pharm 2020;12:237-41.

21. Sadhasivam S, Savitha S, Wu CJ, Lin FH, Stobinski L. Carbon encapsulated iron oxide nanoparticles surface engineered with polyethylene glycol-folic acid to induce selective hyperthermia in folate over expressed cancer cells. Int J Pharm 2015;480:8-14.

22. Rahme K, Chen L, Hobbs RG, Morris MA, O'Driscoll C, Holmes JD. PEGylated gold nanoparticles: polymer quantification as a function of PEG lengths and nanoparticle dimensions. RSV Adv 2013;3:6085-94.

23. Souto AA, Carneiro MC, Seferin M, Senna MJH, Conz A, Gobbi K. Determination of trans-resveratrol concentrations in brazilian red wines by HPLC. J Food Compost Anal 2001;14:441-5.

24. Marcsek ZL, Kocsis Z, Szende B, Tompa. Effect of formaldehyde and resveratrol on the viability of Vero, HepG2, and MCF-7 cells. Cell Bio Int 2007;31:1214-9.

25. Washington KE, Kularatne RN, Biewer MC, Stefan MC. Combination loading of doxorubicin and resveratrol in polymeric micelles for increased loading efficiency and efficacy. ACS Biomater Sci Eng 2018;4:997-1004.

26. Yang G, Xiang S, Zhang K, Gao D, Zeng C, Zhao F. Breast cancer imaging with fluorescein isothiocyanate-modified gold nanoparticles in vitro and in vivo. Int J Clin Exp Med 2016;9:753-9.

27. Larasati YA, Putri DDP, Utomo RY, Hermawan A, Meiyanto E. Combination of cisplatin and cinnamon essential oil inhibits HeLa cells proliferation through cell cycle arrest. J Appl Pharm Sci 2014;4:14-9.

28. Chatterjee K, Al-Sharif D, Mazza C, Syar P, Al-Sharif M, Fata JE. Resveratrol and pterostilbene exhibit anticancer properties involving downregulation of HPV oncoprotein E6 in cervical cancer cells. Nutrients 2018;10:243.

29. Capek I. Chapter 2: noble metal nanoparticles. Nan Sci Tech; 2017. p. $125-210$

30. Liu F, Deng D, Chen X, Qian Z, Achilefu S, Gu Y. Folatepolyethylene glycol conjugated near-infrared fluorescence probe with high targeting affinity and sensitivity for in vitro early tumor diagnosis. Mol Imaging Biol 2010;12:595-607.

31. Hao J, Tong T, Jin K, Zhuang Q, Han T, Bi Y, et al. Folic acidfunctionalized drug delivery platform of resveratrol based on Pluronic 127/D- $\alpha$-tocopheryl polyethyle glycol 1000 succinate mixed micelles. Int J Nanomed 2017;12:2279-92.

32. Kakkar D, Tiwari AK, Chuttani K, Kumar R, Mishra K, Singh H, et al. Polyethylene-glycolylated isoniazid conjugate for reduced toxicity and sustained release. Ther Delivery 2011;2:205-12.

33. Jain S, Rathi VV, Das M, Godugu C. Folate-decorated PLGA nanoparticles as a rationally designed vehicle for the oral delivery of insulin. Nanomedicine 2012;7:1311-37.

34. Danaei M, Dehghankhold M, Ataei S, Davarani FH, Javanmard R, Dokhani A, et al. Impact of particle size and polydispersity index on the clinical applications of lipidic nanocarrier systems. Pharmaceutics 2018;10:57.

35. Sun D, Kang S, Liu C, Lu Q, Cui L, Hu B. Effect of zeta potential and particle size on the stability of $\mathrm{SiO}_{2}$ nanospheres as carrier for ultrasound imaging contrast agents. Int J Electrochem Sci 2016;11:8520-9.

36. Fröhlich E. The role of surface charge in cellular uptake and cytotoxicity on medical nanoparticles. Int J Nanomed 2012;7:5577-91.

37. Toy R, Peiris PM, Ghaghada KB, Karathanasis E. Shaping cancer nanomedicine: the effect of particle shape on the in vivo journey of nanoparticles. Nanomed (Lond) 2014;9:121-34.

38. Chithrani BD, Ghazani AA, Chan WCW. Determining the size and shape dependence of gold nanoparticle uptake into mammalian cells. Nano Lett 2006;6:662-8.

39. Leamon CP, Low PS. Folate-mediated targeting: from diagnostic to drug and gene delivery. Drug Discovery Today 2001;6:44-51.

40. Sulaiman M, Sutriyo S, Mun'im A. Preparation and cytotoxic activity of resveratrol-gold nanoparticles conjugated to folic acid against MCF-7 cell line. J Res Pharm 2019;23:927-34.

41. Wamsley A. Chapter 12: ligand-based targeting approaches to drug delivery. Design of Controlled Release Drug Delivery Systems. California: McGraw-Hill; 2006.

42. Rosenblum D, Joshi N, Tao W, Karp JM, Peer D. Progress and challenges towards targeted delivery of cancer therapeutics. Nat Commun 2018;9:1410.

43. Kumar P, Roy I. Applications of gold nanoparticles in clinical medicine. Int J Pharm Pharm Sci 2016;8:9-16. 